University of Nebraska - Lincoln

DigitalCommons@University of Nebraska - Lincoln

2008

Twin Studies, Molecular Genetics, Politics, and Tolerance: A Response to Beckwith and Morris

John R. Alford

Rice University

Carolyn L. Funk

Virginia Commonwealth University

John R. Hibbing

University of Nebraska-Lincoln, jhibbing1@unl.edu

Follow this and additional works at: https://digitalcommons.unl.edu/poliscifacpub

Part of the Political Science Commons

Alford, John R.; Funk, Carolyn L.; and Hibbing, John R., "Twin Studies, Molecular Genetics, Politics, and Tolerance: A Response to Beckwith and Morris" (2008). Faculty Publications: Political Science. 32. https://digitalcommons.unl.edu/poliscifacpub/32

This Article is brought to you for free and open access by the Political Science, Department of at DigitalCommons@University of Nebraska - Lincoln. It has been accepted for inclusion in Faculty Publications: Political Science by an authorized administrator of DigitalCommons@University of Nebraska - Lincoln. 


\title{
Twin Studies, Molecular Genetics, Politics, and Tolerance: A Response to Beckwith and Morris
}

\author{
John R. Alford, Carolyn L. Funk, and John R. Hibbing
}

\begin{abstract}
Beckwith and Morris raise concerns about the value of twin studies for understanding the role of genetics in complex human behavior, but virtually all of their concerns have been raised and rebutted before. When it comes to the equal environments assumption (EEA), the best approach is to test for and control possible violations of the EEA on heritability estimates rather than merely rejecting all empirical evidence because of the possibility of EEA violations. In many respects, since the study of the genetic basis of complex human behaviors now includes many methods in addition to twin studies, Beckwith and Morris's critique applies more to the behavioral genetics of a quarter century ago than to today's multifaceted behavioral genetics. Twin studies establish that there is a sizeable genetic component to political orientations, thereby giving cause to look further at the nature of that role by using other methodologies, including molecular genetics. We conclude by pointing out that the normative implications of the relevance of genes to human behavior are not nearly as worrisome as Beckwith and Morris seem to believe.
\end{abstract}

W e welcome the opportunity to answer Beckwith and Morris's (hereafter BM) critique of the equal environments assumption (EEA) made by classic twin studies in general and our 2005 American Political Science Review article in particular. Their essay is a focused, if selective, review of the literature and is delivered in an appropriately professional tone, free from the somewhat feverish quality that has characterized other reactions to Alford, Funk, and Hibbing (AFH). Our brief rebuttal speaks to the following: the proper place of the twin methodology in addressing questions about the role of genetics in political behavior, corrections to BM's claims about our research, and scientific responses to concerns about the EEA.

\section{The Equal Environments Assumption}

Virtually all of BM's concerns with twin studies have been raised and rebutted before. Rather than continue to rehash these same disagreements, we will only call attention to a few specific inadequacies in BM's presentation and then

\footnotetext{
John R. Alford is Associate Professor of Political Science, Rice University (jra@rice.edu). Carolyn L. Funk is Associate Professor in the Wilder School of Government and Public Affairs, Virginia Commonwealth University (clfunk@vcu.edu).John R. Hibbing is the Foundation Regents Professor of Political Science, University of Nebraska-Lincoln (jhibbing@unl.edu)
}

note that concerns about the EEA require empirical tests (not just hand-wringing) appropriate to the trait being studied. For more on the EEA, we refer interested readers to the extensive literature in the leading journals of the field, particularly Behavior Genetics and Twin Research, to the papers presented annually at the meetings of the Behavioral Genetics Association, and to the leading texts of behavior genetics. ${ }^{1}$ There will be found honest attempts to wrestle with the limitations of the twin design along with empirical tests (with samples drawn from around the world) of its assumptions. The strong conclusion in this literature is that twin studies are quite valuable even as the optimal approach is to use them in combination with other techniques. This is why twin studies have long been a central tool for human geneticists.

As is typical of critics of twin studies, BM focus their fire on the EEA. One powerful test of the EEA is made possible by virtue of the fact that the zygosity of twins is often miscategorized. When some dizygotic (DZ) twins are believed by those in their environment to be monozygotic (MZ) twins and when some MZ twins are believed by those in their environment to be $\mathrm{DZ}$ twins, it becomes possible to determine if actual zygosity rather than perceived zygosity explains variations in similarity. Results from these creative studies, many of which are cited in both $\mathrm{AFH}$ and $\mathrm{BM}$, consistently indicate the preeminence of actual zygosity and thus support the finding that genetic similarity rather than only perceived similarity accounts for the greater concordance between MZ compared to DZ twins on the trait studied. 
BM reject this whole methodological approach to testing the EEA for reasons that we find perplexing. They suggest that perceived zygosity cannot be treated as a "true surrogate for environmental similarity" without further checks that perceived zygosity is associated with perceived similarity. And, if that kind of "manipulation check" is not enough they dismiss measures of perceived zygosity as unreliable retrospective reports and suggest that all past efforts to empirically test the EEA are inadequate due to small samples and limited statistical power. In the end, BM seek to discredit this kind of evidence with the very "intellectual acrobatics" they attribute to others.

There are a number of empirical approaches to testing and controlling for possible violations of the EEA on heritability estimates. One powerful technique estimates heritability for samples of twins reared apart. ${ }^{2}$ Recent work by Fowler, Baker, and Dawes includes specific tests of the EEA; they find that differences in concordance between $\mathrm{MZ}$ and $\mathrm{DZ}$ pairs on vote turnout cannot be explained by mean differences in turnout rates, party membership, education, personality, or other socioeconomic factors. ${ }^{3}$ Other studies have controlled for the extent of contact between twins when estimating heritability ${ }^{4}$ or controlled for the EEA by using structural equation models that include parents and non-twin siblings. ${ }^{5}$ In fact, thanks to recent advances in genotyping, the days of needing to rely on the natural experiment afforded by twins may soon be over, rendering moot BM's concerns with the varying environmental similarities for $\mathrm{MZ}$ and for $\mathrm{DZ}$ twins. Using nontwin siblings rather than twin-pairs, Visscher et al. recently derived heritability estimates for selected phenotypes (e.g., height) similar to those produced by twin analyses. ${ }^{6}$

Importantly, BM never provide any evidence that the EEA is violated with regard to the trait of interestpolitical orientations. As BM note, previous research has established the importance of treating potential violations of the EEA on a trait by trait basis, so their critique should contain evidence showing, say, that parents of MZ twins are more eager for their twins to be politically similar than are the parents of DZ twins. Until they do so, we stand by our statement that there is currently no such evidence, particularly since previous research finds that the extent of co-twin generic contact (something that is higher for MZ than for $\mathrm{DZ}$ twins) does not predict the extent of political similarity. ${ }^{7}$ The larger point is that instead of criticizing previous examinations of the EEA as it pertains to political orientations, BM should busy themselves conducting the empirical tests they believe necessary.

Since their essay is offered as a critique, BM's own theory of the causes of human behavioral variation remains unclear. They do not disagree that genetic factors are relevant to human behavioral traits, but they want to believe that our findings result either from variations in shared physical features or from the closer bonds between $M Z$ relative to $\mathrm{DZ}$ twins. Because they agree that in order for an EEA violation to inflate estimates of heritability the violation must be trait specific, we consider their two suggestions as they apply to adult political orientations. First, consider the implications of the BM model in which shared visible physical features, such as obesity or attractiveness, lead to more similar "responses of family and society" and these responses in turn lead to more similar adult political attitudes. The most obvious requirement for confirmation of this model is a link between physical appearance and adult political attitudes powerful enough to account for the roughly 40 percent of the variation that our estimates assign to genetic heritability. Physical appearance is certainly a novel independent variable for a model explaining variations in political attitudes, but it is easily testable, and we encourage just such an effort to connect the endpoints of the twin study finding by providing an explicit and empirically-supported chain of intervening variables. Though we think the paths from genes to attitudes probably involve mediation by brain activation patterns (note that the neurotransmitters pertinent to these patterns are no less physically instantiated than the genetically influenced proteins relevant to obesity), the alternative path through physical appearance that BM suggest should not be ruled out absent further empirical evidence. If such a model receives empirical support, however, it would provide just as much validation of the twin study results; it would simply specify the route from genes to political attitudes as traveling through physical appearance rather than through the central nervous system. Either model suggests a much larger role for genetic influence in explaining individual variation in political orientations than current thinking in political science supposes.

BM's other suggestion is that the closer and more frequent interactions between MZ compared to DZ twins constitute a trait-specific violation of the EEA. They offer no explanation for this tendency toward more MZ interaction but presumably it must arise in some way from the relatively higher degree of genetic similarity between MZ twins. They apparently believe this increase in interaction in turn leads to greater similarity in adult political beliefs. There is actually substantial extant research on ideological similarity and the degree of interpersonal interaction. Individuals with similar political orientations have more frequent discussions with each other about politics, are more likely to live near each other, and are even more likely to mate with each other. ${ }^{8}$ In contrast to BM, most of this research has suggested that the main causal arrow runs from political similarity to increased interaction, and not the other way around, but that is an empirical question that existing techniques for studying political behavior are capable of addressing. More important is that again, even if $\mathrm{BM}$ were to prove correct, the results are every bit as much a validation of the twin study results as would be the case if the casual flow ran in the reverse direction from similarity to closer interactions. A model of adult political 
attitudes in which an inherent tendency to interact more closely with genetically similar individuals accounts for more than a third of the variation in those attitudes is a model in which genes play a much more substantial role in influencing political beliefs than current thinking in political science supposes.

\section{Heritability Coefficients and Genetic Determinism}

BM allege that AFH claim political attitudes are "highly heritable" and thus "strongly influenced by genetics"; they are apparently concerned about research suggesting "more deterministic views of genetic influence." BM appear to mischaracterize our research as reflecting a genetic determinism. In fact, we report a heritability estimate for political ideology that shows a sizeable effect (.43) but one that hardly implies all variance is explained by genetic factors (according to the estimate reported in AFH, 57 percent of the variance is attributed to environmental influences). The charge of genetic determinism is a straw man. We certainly do not believe genes "determine" central aspects of complex human behavior (.43 does not equal 1.0) and we know of no modern behavioral geneticist who does. Indeed, the only determinists we know are environmental determinists and they come in three forms: those who actively deny any role at all for genetic effects, those who passively deny a role by consistently engaging in research that focuses exclusively on environmental causes, and those like BM who grudgingly acknowledge that genes play a role but then proceed to discourage any and all research explicating that role. BM's message seems to be that we should avoid learning anything about this recognized explanatory variable, thus dooming the entire enterprise to rampant specification error and ignoring the fact that it is impossible to rule out genetic effects without testing for those effects.

In truth, we do not put a great deal of stock in the precise point estimates of heritability provided by isolated twin studies - in part for the reasons suggested by BM. Twin studies generate population-specific results, meaning that the estimates hold only for the population studied; a different sample of twins (and different statistical estimation techniques) might result in different specific heritability estimates. The EEA is problematic for some traits, and twin studies on their own ignore important confounds such as assortative mating and gene by gene as well as gene by environment interactions. No single coefficient can accurately capture the precise global influence of genetics on political attitudes, but we can say this: The large variety of empirical studies conducted with different samples in different countries that all report substantial (often in the .4 range) levels of heritability for political attitudes ${ }^{9}$ indicates that the genetic contribution to variations in political orientations is significantly greater than zero and may even approach .5. So saying hardly makes us determinists but it does encourage us to call for a reorientation of the common (and unsubstantiated) social science assumption that the only valid independent variable is an environmental variable.

\section{Beyond Twin Studies to Molecular Genetics}

The role of genetics in complex human behavior is being assessed with an ever-growing number of techniques. We believe twin studies are more valuable than is claimed by BM but for a variety of reasons an exclusive reliance on twin studies would be limiting. We fully support the use of multiple methodologies in this and other social science research. Twin studies establish that there is a genetic component to political orientations. This empirical evidence of a role for genetics gives us cause to look further at the nature of that role using other methodologies. Fortunately, valuable approaches to enhancing understanding of the role of genetics are springing up all the time and, with geneticists Nicholas Martin of the Queensland Institute of Medical Research and Lindon Eaves of the Virginia Institute for Psychiatric and Behavioral Genetics (both former presidents of the Behavior Genetics Association) as well as others, including Peter K. Hatemi and Kevin B. Smith, we are pursuing several of these.

One approach involves beginning with twin data but then adding data on non-twin siblings and parents to create an extended nuclear family model, thereby making it possible to test many of the concerns surrounding the equal environments assumption of the classic twin design (since non-twin sibs share roughly similar environments as their twin siblings). ${ }^{10}$ Another approach this team is employing involves DNA analysis using genome-wide scans (both genome-wide linkage scans and genome-wide association scans). Because so many markers have been identified at various points around the human genome, it is now possible to look for correlations between genetic variations throughout the genome and, in this case, political phenotypes. Such techniques can be facilitated if close relatives are in the sample (thus making population stratification easier) but do not require twins and are not reliant on the EEA. Our preliminary results are promising. Finally, members of this same team are conducting allelic association tests. This is a technique in which variations at a particular genetic locus (say in or near a gene known to be involved in the transport of the neurotransmitter serotonin) are checked for association with phenotypic variations such as participating in politics or subscribing to a certain set of political views. Here again, preliminary results of ours as well as of others are promising. ${ }^{11}$ Adoption studies constitute yet another approach that could be employed by those who believe the assumptions behind twin studies are violated. 
The study of the genetic basis of complex human behaviors goes well beyond twin studies and in many respects BM's critique applies more to the behavioral genetics of a quarter century ago than to today's multifaceted behavioral genetics. BM claim that "problems with scientific data" make the move toward incorporating genetic factors into existing environmental accounts of political variations "premature" but beyond twin studies they display no awareness of any of the currently employed techniques, especially those involving molecular genetics. Moreover, we are left wondering if in BM's view the time will ever be right-particularly if we follow their advice and continue to ignore genetic factors in favor of merely developing ever "more sophisticated measures of the environment."

\section{Science, Tolerance, and Scientific Tolerance}

The underlying issue in BM's critique of course is not conflicting assessments of the severity of violations of a single assumption of one particular research methodology. Rather, it is whether widespread acceptance of the fact that genetics plays an influential role in accounting for variations in human behavior will make the world a better or worse place. Jon Beckwith believes such recognition will be deleterious. For decades, this self-described "social activist" has chosen to "focus on ideological stances." 12 Though we respect his sincere commitment to an ideological cause, we believe this approach is misguided on at least two counts.

Accepting empirical evidence of the role of genetics in human behavior does not constitute doomsday. Contrary to Beckwith's belief, evidence of the role of genetics in human behavior holds the promise of creating a more tolerant world. Consider the revolution-beginning in the late 1960 s - in the way schizophrenia was understood. Prior to this time, the assumption of the psychological community was that schizophrenia was entirely the product of environmental forces. Generations of parents of schizophrenics were made to feel they had failed their children by not providing a proper environment. Soon, however, careful scientific research - much of it based on twin studies (the heritability coefficient for schizophrenia is .62) indicated the strong role played by genetics. ${ }^{13}$ It cannot accurately be said that attitudes toward schizophrenics and their parents now are less compassionate than was the case when people claimed that only the environment mattered. Today, much the same contours can be found in debates over the causes of variations in sexual preferences. Presumably, Beckwith feels it is as "premature" to look for genetic correlates of sexual preferences just as he believes it is "premature" to look for the genetic correlates of political preferences. But note that those least tolerant of homosexuality tend to believe sexual prefer- ence is environmentally determined, while those who are open to the possibility that genes also affect sexual preferences are usually more tolerant of variations in them.

The second reason Beckwith's concerns are misplaced is that science ultimately does not let humans select the truths preferred. If it did, we would still believe the Earth was the center of the solar system and that man was not descended from other primates. Sticking our heads in the sand rather than watching as the crucible of competing discoveries illuminates the sources of human variation is not a viable approach to scientific inquiry. If Beckwith is correct, he has no reason to worry because science will show that genes are indeed largely irrelevant to complex human behavior; if we are correct, the next decade will be characterized by new discovery after new discovery demonstrating that human behavior is a fascinating interaction of genetic and environmental forces.

To be sure, any knowledge can be dangerous but this dictum applies as much to environmental as genetic variables. Is it really possible to say that the radical social engineering of Mao in which 20 million people may have died was better or worse than the misguided genetic theories that likewise contributed to the deaths of millions in Europe a few decades earlier? Intolerant people are unlikely to be made tolerant if one justification for intolerance is removed from them. In service to their own particular "ideological stances," BM offer an anachronistic vision of the causes of human behavioral variation that rejects empirical evidence and scientific methodologies out of hand without providing any empirical alternatives. We prefer to follow science where it leads even as there is no guarantee we will be pleased with the final destination.

\section{Conclusion}

Taken at their word, both twin studies researchers and twin studies detractors agree on the crucial issue. Each side believes that variations in political attitudes and behavior arise from both genetic and environmental variations (and critically from the interactions of genes and environments). Casual readers then could not be blamed for puzzling over the persistence of the heated disagreement. In our view it is this: Critics of behavioral genetics research are aware that purely environmental accounts of variations in human behavior (political and otherwise) are not scientifically tenable today. This alone constitutes a shift in social science thinking of tectonic proportions. What BM apparently do not accept is that this acknowledged influence of genetic variation operates through physiological variations in brain structure or function. Thus they advance models of genetic impact that they find more palatable, such as that all of the effects of genetic variation on behavior are mediated by outward physical appearance. BM's efforts to mold empirical evidence to fit their pre-existing ideological sensibilities come at a high cost. 
Not only are they forced to concoct dubious distinctions between the physicality (and therefore the potential genetic basis) of outward appearance and the physicality of the central nervous system, they are forced to advance novel theories about the connection of physical appearance to politics. These theories are intriguing but BM would further the scientific process much more by testing these eminently testable theories than by recycling decades-old complaints directed at the standard empirical techniques of behavioral genetics.

\section{Notes}

1 Carey 2003; Plomin et al. 2008.

2 Bouchard et al. 1990.

3 Fowler, Baker, and Dawes 2008.

4 Martin et al. 1986.

5 Hatemi et al. 2007.

6 Visscher et al. 2006.

7 Martin et al. 1986.

8 Huckfeldt, Johnson, and Sprague 2004; Oppenheimer 2005; Mutz 2006.

9 Martin et al. 1986; Eaves et al. 1999; Olson et al. 2001; Bouchard and McGue 2003.

10 Hatemi et al. 2007.

11 Settle et al. 2008.

12 (http://www.lbl.gov/Science-Articles/Archive/ Beckwith-genetics.html).

13 Gottesman 1991.

\section{References}

Alford, John R., Carolyn L. Funk, and John R. Hibbing. 2005. Are political orientations genetically transmitted? American Political Science Review 99 (2): 153-68.

Bouchard, T.J., Jr., D.T. Lykken, M. McGue, N.L. Segal, and A. Tellegen. 1990. Sources of human psychological differences: The Minnesota Study of Twins Reared Apart. Science 12 (October): 223-28.

Bouchard, T.J., Jr., and Matt McGue. 2003. Genetic and environmental influences on human psychological differences. Journal of Neurobiology 54: 4-45.

Carey, Gregory. 2003. Human Genetics. Thousand Oaks, CA: Sage.

Eaves, L.J., A.C. Heath, N.G. Martin, H.H. Maes, M.C. Neale, K.S. Kendler, K.M. Kirk, and L. Corey. 1999. Comparing the biological and cultural inheritance of personality and social attitudes in the Vir- ginia 30,000 study of twins and their relatives. Twin Research 2 (June): 62-80.

Fowler, J.H., L.A. Baker, and C.T. Dawes. 2008. Genetic variation in political participation. American Political Science Review 102 (2): 233-48.

Gottesman, I.I. 1991. Schizophrenia Genesis: The Origins of Madness. New York: Freeman.

Hatemi, Peter K., John R. Alford, John R. Hibbing, Sarah E. Medland, Matthew C. Keller, Nicholas G. Martin, and Lindon J. Eaves. 2007. "Not by Twins Alone: Using the Extended Family Design to Investigate the Genetic Basis of Political Beliefs." Presented at the annual meeting of the Midwest Political Science Association, Chicago, April $12-15$.

Huckfeldt, Robert, Paul Johnson, and John Sprague. 2004. Political Disagreement: The Survival of Diverse Opinions within Communication Networks. Cambridge, UK: Cambridge University Press.

Martin, N.G., L.J. Eaves, A.C. Heath, R. Jardine, L.M. Feingold, and H.J. Eysenck. 1986. Transmission of social attitudes. Proceedings of the National Academy of Sciences (15 June): 4364-68.

Mutz, Diana C. 2006. Hearing the Other Side. Cambridge UK: Cambridge University Press.

Olson, James M., Philip A. Vernon, Julie Aitken, and Kerry L. Jang. 2001. The heritability of attitudes: A study of twins. Journal of Personality and Social Psychology 80: 645-60.

Oppenheimer, Bruce I. 2005. Deep red and blue congressional districts. In Congress Reconsidered, ed. Lawrence C. Dodd and Bruce I. Oppenheimer. 8th ed. Washington, DC: Congressional Quarterly Press.

Plomin, Robert, John D. DeFries, Gerald E. McClearn, and Peter McGuffin. 2008. Behavioral Genetics. 5th ed. New York: Worth.

Settle, Jaime E., Christopher T. Dawes, Nicholas A. Christakis, and James H. Fowler. 2008. "Friendships Moderate an Association between the DRD4 Gene and Political Ideology." Working paper, University of California-San Diego.

Visscher, Peter M., Sarah E. Medland, Manuel A. R. Ferreira, Katherine I. Morley, Gu Zhu, Belinda K. Cornes, Grant W. Montgomery, Nicholas G. Martin. 2006. Assumption-free estimation of heritability from genome-wide identity-by-descent sharing between full siblings PLoS Genetics 2 (3): 316-24. 